\title{
LA TRANSVERSALIDAD Y LA LONGITUDINALIDAD DEL SER HUMANO
}

Ana Teresa López de Llergo Villagómez

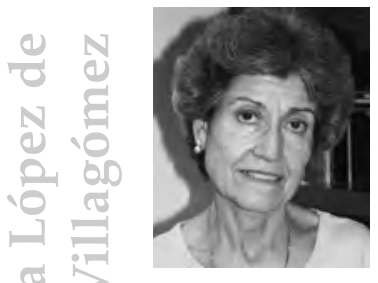

Doctorado en Ciencias de la Educación, Universidad de Navarra. Maestría en Pedagogía, Universidad Panamericana. Licenciatura en Ingeniería Química y Química Industrial, Universidad Iberoamericana. Directora de Difusión Cultural, Universidad Panamericana. Autora de: Hacia un desarrollo humano, Ed. Limusa; Valores, valoraciones y virtudes, Ed. CECSA.

Correo electrónico:[alopzde@up.edu.mx]

\section{INTRODUCCIÓN}

Lo transversal corta perpendicularmente algún objeto. La descripción transversal de una persona explica las capas que la conforman. Por eso, la caracterología señala los componentes del modo de ser, desde los más externos hasta los más profundos. Esta perspectiva corresponde a la transversalidad de alguien.

La longitud señala una distribución secuencial, y al referir lo longitudinal al ser humano, obviamente se hace referencia a la serie de acontecimientos sucesivos en el tiempo. Es así que podríamos decir 
que la psicología evolutiva nos relata los cambios producidos en la persona en el transcurso de los años. Esto equivale a la «longitudinalidad» del ser humano.

Así, el estudio del ser humano requiere de la explicación de su modo de ser caracterial, para comprender sus respuestas y la influencia de la experiencia acumulada a través de los años. Caracterología y psicología evolutiva son dos estudios que nos muestran la riqueza y singularidad de toda persona.

Sin embargo, también hace falta estudiar los efectos de las relaciones interpersonales y, sobre todo, la eficacia de la influencia educativa cuando parte del conocimiento del estado en que se encuentra cada quién.

\section{DOS LIBROS, DOS ENFOQUES, AMBOS COMPLEMENTÁNDOSE}

Caracterología relacional ${ }^{1}$ explica el sustrato temperamental con el cual cada persona nace; es la herencia desde donde parte el desenvolvimiento e indica los límites y las posibilidades. Es relacional porque toma muy en cuenta la influencia de los demás, tanto desde el punto de vista estimulante como el paralizante. El otro texto es el de Las etapas de la vida ${ }^{2}$, en donde se exponen las características propias de cada período, desde la etapa prenatal hasta la cuarta edad. En los dos libros hay una explicación educativa para impulsar a la mejora: precisamente para superar los obstáculos. En los dos se incluyen lecturas para ejemplificar los postulados; en el de caracterología se presentan biografías, en el de psicología evolutiva, las lecturas relatan sucesos de personajes con una determinada edad.

- CRUZ DE GALINDO, Luz María y LÓPEZ DE LLERGO, Ana Teresa, Caracterología relacional. Una guía para la optimización de las relaciones humanas, Trillas, México, 2009, 206 p.

2 CRUZ DE GALINDO, Luz María y LÓPEZ DE LLERGO, Ana Teresa, Las etapas de la vida. Cómo entender los cambios, el reto de vivir con significado y las crisis de cada etapa. Trillas, México, 2008, 138 p. 


\section{CARACTEROLOGÍA RELACIONAL}

La Introducción analiza el propósito del libro:

En la primera parte, a través de las biografías se describe el modo de ser; en la segunda, el de relacionarse. La idea es ver cómo estas relaciones son posibles y satisfactorias de forma espontánea y cuándo son naturalmente difíciles. Se pretende así ayudar a la persona a conocerse y a poner los medios para que la convivencia con los otros sea lo más armónica posible.

Las afinidades y los antagonismos caracterológicos tienen gran trascendencia, pero hay situaciones que, de manera especial, influyen en la vida futura, por ejemplo, durante el noviazgo, pues predicen la convivencia en la vida matrimonial. En relaciones no elegidas, pero importantísimas (hijos, padres, familia extensa) es posible atenuar los conflictos y las incomprensiones cuando las personas conocen el propio carácter y el de los demás.

En la tercera parte de este libro se considera la relativa plasticidad de los elementos del carácter, así como sus fortalezas y áreas de oportunidad, y se presentan algunas recomendaciones para encauzarlos y compensarlos a fin de lograr cierta madurez personal que prevenga roces y malentendidos, por la espontaneidad del propio modo de ser y sus repercusiones en la convivencia. En un anexo se presenta un cuestionario caracterológico.

La primera parte, titulada "Cómo soy», explica los elementos constitutivos fundamentales del modo de ser: emotividad, actividad y resonancia, y cómo la combinación de estos elementos produce ocho tipologías. También se le otorga relevancia a los elementos complementarios que acentúan o atenúan los elementos fundamentales. Y son: amplio o estrecho en el campo de conciencia; ávido o no ávido de posesiones y de reconocimiento; egocéntrico o alocéntrico, en las relaciones con los demás; dominante o conciliador en el trato; introvertido o extravertido respecto a la intimidad; tierno o seco afectivamente; inapetente o apetente de intereses sensoriales.

La segunda parte, «Cómo somos», contiene el estudio de la dinámica entre los emotivos, la dinámica entre los no emotivos, y la dinámica entre emotivos y no emotivos. 
En la tercera parte, «Orientaciones educativas», se proporcionan sugerencias para ayudar a cada una de las ocho tipologías y, también, para aprovechar de la mejor manera los elementos complementarios.

\section{LAS ETAPAS DE LA VIDA}

En la Presentación se explica:

Todos tenemos un pasado, un presente y un futuro, en distintas proporciones según la distancia del presente con nuestra fecha de nacimiento. Sin embargo, en la historia personal hay rasgos comunes, propios del género humano: la infancia se caracteriza por un pasado muy breve, se ha experimentado poco, la reflexión es escasa y se vive con intensidad el presente. Las huellas que quedan de esa época son muy profundas, pues es lo primero que se escribe en la biografía de cada uno (aunque pocas veces hagamos conciencia de ello), por lo cual, tarde o temprano se manifiestan en la vida futura y van señalando las diferencias en el modo de ser de cada quien.

[...] De manera esquemática podemos comenzar afirmando que la trayectoria del ser humano empieza con la no advertencia de su existir (recién nacido); con el tiempo, poco a poco va alcanzando una cierta conciencia de sí (infancia), hasta llegar a la toma de conciencia del yo (adolescencia). Más adelante (juventud y adultez) ese ser humano descubre que está inmerso en las relaciones con otros yos. Por último, llega la decadencia del yo y una mayor dependencia hacia los demás (tercera y cuarta edades). Cada etapa de la vida es diferente de las otras, pero cada una tiene sentido en sí misma y, a la vez, debe servir de preparación para la siguiente.

Desde luego que el tránsito de una etapa a otra adquiere un sentido mucho más enriquecedor y una dimensión más profunda si quien lo experimenta ha logrado una visión trascendente completa, la cual se adquiere cuando las convicciones religiosas o espirituales dejan su impronta en el diario vivir. Esto da una solidez especial para afrontar y resolver las crisis naturales, que por lo común se presentan para acceder a la siguiente etapa. 
La etapa prenatal conlleva la crisis del alumbramiento y el logro consiste en el hecho de nacer e independizarse. La infancia, con sus tres subgrupos, comporta el crecimiento, la individualidad y el autodescubrimiento con el resultado del dominio sensoriomotriz, la distinción de los demás y la ubicación en el entorno próximo.

La pubertad propicia el autoconocimiento y el descubrimiento de la intimidad. La adolescencia, dividida en dos etapas, primero lleva al aislamiento y luego al redescubrimiento de la intimidad; poco a poco se logra una expresión adecuada de la afectividad, el autodominio y cierto equilibrio emocional.

La juventud pasa del idealismo al realismo de afrontar la existencia. La adultez, en la década de los treinta años, sufre la experiencia de los límites de las propias elecciones y lo deseable es conseguir la fidelidad a los compromisos asumidos. La década de los cuarenta ofrece la experimentación de los propios límites y el proceso de aceptación de ese modo de ser. En la década de los cincuenta inicia el desplazamiento por los más jóvenes y lo deseable es una ubicación serena. El quinquenio de los sesenta a los sesenta y cinco demanda desasimiento y compartir la experiencia acumulada.

La tercera edad cuenta con la década de los sesenta y seis a los setenta y cinco años, aquí aparecen el deterioro y la pérdida; para recorrer esta etapa es necesaria la reorganización de las actividades. La siguiente década, de los setenta y seis a los ochenta y cinco años, consiste en el franco envejecimiento y exige la aceptación de la necesaria dependencia.

Finalmente, la cuarta edad, de los ochenta y cinco años en adelante, lleva a la irrealidad compensada con la humilde confianza en los demás. 


\section{CONCLUSIÓN}

La vida humana encierra una infinidad de reductos, todos ellos llenos de encanto y novedad. Por eso, de cada etapa podemos sacar muchas consecuencias educativas. Cada persona es una muestra singular de una sugerente manera de recorrer el camino y de un sorpresivo ingenio para afrontar los retos. 